\title{
Perioperative fasting time among cancer patients submitted to gastrointestinal surgeries
}

\author{
Avaliação do tempo de jejum entre pacientes submetidos a \\ cirurgias do trato digestório em um hospital oncológico \\ Tiempo de ayuno perioperatorio entre pacientes con cáncer \\ sometidos a cirugías gastrointestinales
}

Nayara de Castro Pereira ${ }^{1}$, Ruth Natalia Teresa Turrini ${ }^{2}$, Vanessa de Brito Poveda ${ }^{2}$

How to cite this article:

Pereira NC, Turrini RNT, Poveda VB. Perioperative fasting time among cancer patients submitted to gastrointestinal surgeries. Rev Esc Enferm USP. 2017;51:e03228. DOI: http://dx.doi.org/10.1590/S1980-220X2016036203228

${ }^{1}$ Universidade de São Paulo, Escola de Enfermagem, São Paulo, SP, Brazil.

${ }^{2}$ Universidade de São Paulo, Escola de Enfermagem, Departamento de Enfermagem Médico-Cirúrgica, São Paulo, SP, Brazil.

\begin{abstract}
Objective: To identify the length of perioperative fasting among patients submitted to gastrointestinal cancer surgeries. Method: Retrospective cohort study, developed by consulting the medical records of 128 patients submitted to gastrointestinal cancer surgeries. Results: The mean of total length of fasting was 107.6 hours. The total length of fasting was significantly associated with the number of symptoms presented before $(p=0.000)$ and after the surgery $(p=0.007)$, the length of hospital stay $(p=0.000)$, blood transfusion $(p=0.013)$, nasogastric tube $(p=0.001)$ and nasojejunal tube $(p=0,003)$, postoperative admission at ICU $(\mathrm{p}=0.002)$, postoperative death $(\mathrm{p}=0.000)$ and length of preoperative fasting $(p=0.000)$. Conclusion: The length of fasting is associated with complications that affect the quality of the patients' postoperative recovery and nurses' work. The nursing team should be alert to this aspect and being responsible for overseeing the patients' interest, should not permit the unnecessary extension of fasting.
\end{abstract}

\section{DESCRIPTORS}

Digestive System Surgical Procedures; Fasting; Perioperative Nursing; Oncology Nursing; Digestive System Neoplasms. 


\section{INTRODUCTION}

Eating difficulties exists among surgical cancer patients, due to physiological factors associated with the disease process or the required fasting time for a range of laboratory and surgical procedures, which can culminate in malnutrition associated with the hospitalization.

Patients with gastrointestinal tumors are predisposed to malnutrition related to the hospitalization itself, aspects associated with the diagnosis (type of tumor, staging, among others) and the treatment (radiotherapy and chemotherapy), which compromise their organism's ability to react to the fasting periods, and affect their postoperative recovery and prognosis ${ }^{(1)}$. It is known that changes in the nutritional condition compromise the functioning of the immune system, increasing the number of healthcare associated infections, the hospitalization period and healthcare costs and affecting negatively the healing ${ }^{(2)}$.

The literature shows the improvement in postoperative recovery and patients' wellbeing related to the reduction of the fasting period by offering a preoperative solution rich in carbohydrates, two to three hours before the induction of anesthesia, shortened fasting length and an early oral nutrition during the postoperative period. All these initiative are linked to The Enhanced Recovery After Surgery (ERAS), a project created to optimize the recovery and perioperative management of surgical patients, and proposing care elements in all perioperative period ${ }^{(3-7)}$.

Reducing preoperative fasting time mitigates the postoperative insulin resistance ${ }^{(3)}$ and does not seem to be associated with complications, such as bronchoaspiration ${ }^{(4)}$ during the anesthetic induction, besides it, reduces the hospital staying without compromising the quality of patient care ${ }^{(5-7)}$.

Despite this, many hospital institutions keep traditional fasting protocols, submitting patients to extended fasting times, between eight or 12 hours. This study was interested to explore the fasting time period at a cancer hospital.

The aims of the study were to identify the length of preoperative fasting and total fasting time in patients submitted to gastrointestinal cancer surgeries and verify the relation between the length of fasting and the independent variables: symptoms, length of stay, blood transfusion, glucose levels, nasogastric/nasojejunal tube.

\section{METHOD}

We performed a retrospective cohort study by consulting the medical records of patients over 18 years old, submitted to gastrointestinal cancer surgeries, between March and April 2014, at an oncology hospital located in the State of São Paulo (Brazil) that does not apply the ERAS protocol.

Linear regression based on nine predictable variables that explain $20 \%$ of the variation in the fasting time was used to calculate the sample. Thus, the initially proposed sample size was 104 patients, adopting a 5\% significance and 95\% power level. The final sample was 128 patients.

Data collection was performed by medical records of patients who met the selection criteria between March and April 2014, since the surgery admission, until the hospital discharge and included sociodemographic variables (sex and age), nutritional (weight, height, body mass index - BMI, nasogastric/nasojejunal tube), laboratory findings (glucose), gastrointestinal symptoms (nausea, vomiting), and variables related to the disease and the health treatment (medical diagnosis; presence of hypertension and/or diabetes mellitus; previous chemotherapy or radiotherapy treatment; preoperative fasting time calculated from the last meal time to induction of anesthesia and total fasting time during the hospitalization, including the preoperative last meal to first solid or liquid intake and fasting before laboratorial tests and/or imaging tests; type of surgery; need of blood transfusion and length of stay).

The data were analyzed using mean, standard deviation (SD), median and range, the Mann-Whitney test, Paired $T$ Test, Kruskal-Wallis Test and Pearson's Correlation. Significance level was set at $\alpha<0.05$.

Approval for the research project was obtained from the Research Ethics Committee, registered number 659.354.

\section{RESULTS}

In the study, 128 patients submitted to gastrointestinal cancer surgeries were included, 77 (60.2\%) of them were male and $51(39.8 \%)$ women, with a mean age of 62.1 years old (Table 1 ).

The weight at the hospital admission was registered for 107 (83.6\%) patients, while the weight at the moment of the postoperative discharge was present in $36(28.1 \%)$ records (Table 1). The mean difference among patients who had the measure of weight on admission and discharge was $1.5 \mathrm{Kg}$. The average length of stay was 15.4 days ( $\mathrm{SD}=13.4)$, the total length of fasting was 107.6 hours (SD=73) or 4.5 days (Table 1 ).

Table 1 - Distribution of patients according to demography and hospitalization variables - São Paulo, São Paulo, Brazil, 2014.

\begin{tabular}{|c|c|c|c|c|}
\hline Variables & N $(\%)$ & Mean $\pm S D$ & Median & Range \\
\hline Female & $51(39.8)$ & & & \\
\hline Male & $77(60.2)$ & & & \\
\hline Age & $128(100)$ & $62.1 \pm 13.2$ & 62 & $19-89$ \\
\hline $\begin{array}{l}\text { Weight upon } \\
\text { admission (Kg) }\end{array}$ & 107 (83.6) & $67.4 \pm 14.3$ & 65.1 & $42-110$ \\
\hline $\begin{array}{l}\text { Body mass index } \\
\left(\mathrm{Kg} / \mathrm{m}^{2}\right)\end{array}$ & 107 (83.6) & $25.2 \pm 4.5$ & 25.0 & $16.4-37.4$ \\
\hline $\begin{array}{l}\text { Weight upon } \\
\text { discharge }(\mathrm{Kg})\end{array}$ & $36(28.1)$ & $68.0 \pm 16.8$ & 65.8 & 41.6-116.4 \\
\hline Length of stay (days) & $128(100)$ & $15.4 \pm 13.4$ & 10.5 & $1-78$ \\
\hline $\begin{array}{l}\text { Hours of } \\
\text { preoperative fasting }\end{array}$ & $117(91.4)$ & $26.4 \pm 47.1$ & 12.2 & $4.0-363.7$ \\
\hline $\begin{array}{l}\text { Total length of } \\
\text { fasting (hours) }\end{array}$ & $121(94.5)$ & $107.6 \pm 73.0$ & 88 & $24-501$ \\
\hline $\begin{array}{l}\text { Length of surgery } \\
\text { (minutes) }\end{array}$ & $114(89.1)$ & $260.1 \pm 159.8$ & 220 & $40-825$ \\
\hline Death & $20(15.6)$ & & & \\
\hline
\end{tabular}

Note: $(\mathrm{n}=128)$

Forty-nine (38.3\%) patients underwent chemotherapy (CT), four (3.1\%) radiotherapy (RT) and 31 (24.2\%) CT and RT. The most frequent chemotherapy drug combination was oxaliplatin, leucovorin, 5 -fluorouracil $(\mathrm{n}=18 ; 14.1 \%)$. 
The main comorbidity identified was Systemic Arterial Hypertension (SAH) in $44(34.4 \%)$ patients and 21 (16.4\%) had both SAH and Diabetes Mellitus (DM).

Among the patients, eight (6.2\%) had their scheduled surgeries canceled, due to administrative problems. All of them were rescheduled and took place afterwards, during the same hospitalization period under analysis.

Preoperative glucose measures were registered in only $22(17.2 \%)$ medical records, with a mean of $134.4 \mathrm{mg} / \mathrm{dl}$ $(\mathrm{SD}=40.8 \mathrm{mg} / \mathrm{dl})$, median $123 \mathrm{mg} / \mathrm{dl}$, range from $71 \mathrm{mg} / \mathrm{dl}$ to $235 \mathrm{mg} / \mathrm{dl}$. Postoperative glucose was registered to 75 (58.6\%) patients, with a mean of $141.8 \mathrm{mg} / \mathrm{dl}(\mathrm{SD}=41.2$ $\mathrm{mg} / \mathrm{dl}$ ), median $138 \mathrm{mg} / \mathrm{dl}$, range from $57 \mathrm{mg} / \mathrm{dl}$ to $275 \mathrm{mg} / \mathrm{dl}$.

The most frequent diagnoses were malignant rectal cancer $(n=40 ; 31.2 \%)$, malignant stomach cancer $(n=19$; $4.8 \%)$ and malignant colon cancer $(n=14 ; 10.9 \%)$. Thus, the most common surgeries were rectosigmoidectomy $(n=26$; $20.3 \%)$, exploratory laparotomy $(n=23 ; 18.0 \%)$, and gastrectomy $(\mathrm{n}=13 ; 10.1 \%)$. Gastrectomy, ileostomy, jejunostomy or colostomys were observed in $19(14.8 \%)$ patients. After the surgery, $70(54.7 \%)$ patients were forwarded to the ward and $58(45.3 \%)$ to the ICU.

At the end of the fasting period, $93(72.7 \%)$ patients returned to the oral feeding, and 14 (10.9\%) started an enteral diet.

Some symptoms were observed as preoperative nausea $(n=21 ; 16.4 \%)$, postoperative nausea $(n=68 ; 53.1 \%)$, preoperative vomiting $(n=26 ; 20.3 \%)$ and postoperative vomiting $(n=52 ; 40.6 \%)$. The nasogastric tube was present in 60 (46.9\%) patients during the postoperative period.

The preoperative length of fast showed a statistically significant association with the length of stay $(p=0.002)$, the number of preoperative symptoms $(\mathrm{p}=0.000)$, nasogastric tube $(p=0.014)$ and the patient's postoperative death $(p=0.015)$.

The total length of fasting was significantly associated with the number of symptoms the patient presented before $(p=0.000)$ and after the surgery $(p=0.007)$, the length of stay $(p=0.000)$, blood transfusion $(p=0.013)$, nasogastric tube $(p=0.001)$, nasojejunal $(p=0.003)$ tube, postoperative ICU admission $(p=0.002)$, patient's postoperative death $(p=0.000)$ and preoperative length of fasting $(\mathrm{p}=0.000)$.

\section{DISCUSSION}

In this study, it was observed that the patients submitted to longer length of fasting had more preoperative and postoperative symptoms, longer hospitalization, postoperative ICU admission, as well as postoperative death. In addition, the preoperative length of fast determined a longer length of total fasting.

The current discussion about the fasting cannot be detached from the Brazilian and international projects aimed at reducing the complications and influencing the postoperative recovery process, through the implementation of a multimodal protocol, which includes the reduction in the preoperative length of fasting and early reintroduction of food ${ }^{(8)}$.

The projects Enhanced Recovery After Surgery (ERAS) and the Brazilian project ACEleração da Recuperação TOtal Pós-operatória (ACERTO - Acceleration of Complete
Postoperative Recovery) intend to optimize the patient's recovery through perioperative care, such as the shortening of fasting, restricted use of nasogastric tube and drains, early return of the diet in the postoperative period, early mobilization ${ }^{(8)}$.

Hence, studies that compared the length of hospitalization between patients operated on after the implementation of the ERAS protocol and patients operated on before its implementation concluded that the period after the start of the protocol entailed a shorter hospitalization and postoperative recovery ${ }^{(9-10)}$. A randomized study also concluded that the ERAS protocol mitigates the surgical stress and accelerates the recovery, without increasing the morbidity and mortality rates ${ }^{(11)}$.

In the same sense, a study on the adherence rate to the ERAS protocol found that, during the years of higher compliance levels, the length of hospitalization dropped when compared to the low compliance periods. The implementation of the protocol reduced the fasting periods and contributed to other aspects that significantly improved the postoperative evolution, such as the reduction of the nasogastric tube use, early oral nutrition and early mobilization ${ }^{(12)}$.

In another study that analyzed a control group that followed traditional fasting, being deprived of food and fluids and an intervention group that received fluids up to two hours before the surgery and solid foods up to six hours, it was verified that the intervention group showed less preoperative symptoms, such as hunger, headache and nausea, besides signs of feeling more comfortable ${ }^{(13)}$. Another prospective study observed that patients who fasted for a shorter period had less postoperative symptoms like nausea and vomiting ${ }^{(14)}$. These aspects were observed in the present study, as patients who fasted longer had more postoperative symptoms like nausea and vomiting, for example.

It should also be highlighted that shorter fasting not only contributes to reduce the length of hospitalization, but entailed the lesser need for blood transfusion, a lesser number of cases of surgical site infections, reduction in the number of intraoperative complications and deaths ${ }^{(8)}$.

Our study pointed out association between fasting time and need for blood transfusion. It is important remember that blood transfusion, among colorectal cancer patients, have been associated with increased length of stay, morbidity, recurrence of tumor, decreased long term survival and death ${ }^{(15-17)}$.

Therefore, it can be deduced that, even if fasting is necessary at some time due to the health condition of gastrointestinal tumor patients, the excessive extension of this fasting time can compromise the recovery, prolongs the hospitalization and increases the chances of complications and even death.

When analyzing these data from the economic viewpoint, shortening the length of fasting contributes to reduce costs, due to the greater bed turnover and reduced length of hospitalization, and earlier hospital discharge $\mathrm{e}^{(8)}$.

The initiative to reduce fasting time is related to a multidisciplinary approach, including nurse, surgeon, anesthetist and nutritionist ${ }^{(18)}$. A real team work is essential to the 
success of this intervention and the nurse is the link of team, managing and executing all care elements, resulting in a fulfillment of protocol. The scientific literature shows that the higher compliance to the ERAS is related to a reduced length of stay and the nursing workload ${ }^{(19-20)}$.

It is important to highlight that there are important activities of nursing that could be implemented during the perioperative period, related to a better quality of life, comfort and satisfaction of patients.

Among this measures, preoperative counseling could contribute to the reduction of pain, anxiety and complications, and increase postoperative self-care ${ }^{(21)}$; the prevention of hypothermia, nausea and vomiting ${ }^{(22)}$ during the intraoperative period; to recognize and treat the postoperative thirst in the Post Anesthetic Care Unit (PACU) a frequent symptom, reaching $100 \%$ of patients with more than eight hours of fasting, that could be safely treated with $2 \mathrm{ml}$ of ice, placed in the patient's mouth to completely dissolve ${ }^{(23)}$; and to encourage oral fluid, feeding and early mobilization to prevent blood clots ${ }^{(22)}$ in clinical ward. All this measures could be safely implemented in many hospitals, with minimal alterations on institutional policies.

\section{CONCLUSION}

In this study, the preoperative length of fasting was significantly associated with the length of hospitalization, the number of preoperative symptoms, nasogastric tubes and death. The total length of fasting was significantly associated with the number of symptoms presented before and after surgery, the length of stay, blood transfusion, nasogastric and nasojejunal tubes, postoperative ICU admission and postoperative death.

The scientific literature show us how extended fasting periods could reverberate on nursing workload. Therefore, the multi-professional team and particularly the nursing staff need to discuss this issue. As patient advocate, the nurses should watch out for continuously unnecessary fasting period for procedures and diagnostic exams and, even when necessary, these fasting periods should be reduced to a minimum, aiming to privilege the patient's recovery.

\section{RESUMO}

Objetivo: Identificar o tempo de jejum perioperatório e sua associação a variáveis pós-operatórias entre pacientes submetidos a cirurgias oncológicas do trato digestório. Método: Estudo de coorte retrospectiva, realizado por meio da consulta a 128 prontuários de pacientes adultos, submetidos a cirurgias oncológicas gastrointestinais. Resultados: $\mathrm{O}$ tempo total de jejum durante a internação foi em média 107,6 horas. O tempo total de jejum foi associado de forma estatisticamente significante ao número de sintomas pré-operatórios ( $\mathrm{p}=0,000)$ e pós-operatórios $(\mathrm{p}=0,007)$, ao período de internação $(\mathrm{p}=0,000)$, à transfusão sanguínea $(\mathrm{p}=0,013)$, ao uso de cateter nasogástrico ( $\mathrm{p}=0,001)$ e nasoentérico $(\mathrm{p}=0,003)$, à admissão pós-operatória em terapia intensiva $(\mathrm{p}=0,002)$, à morte pós-operatória $(\mathrm{p}=0,000)$ e à duração do jejum pré-operatório $(\mathrm{p}=0,000)$. Conclusão: A duração do jejum é associada a complicações que afetam a qualidade da recuperação do paciente e o trabalho da enfermagem. A equipe de enfermagem deve estar atenta a esse aspecto, uma vez que, como responsável pela vigilância dos interesses dos pacientes, não deve permitir o prolongamento desnecessário do período de jejum.

DESCRITORES

Procedimentos Cirúrgicos do Aparelho Digestivo; Jejum; Enfermagem Perioperatória; Enfermagem Oncológica; Neoplasias do Sistema Digestivo.

\section{RESUMEN}

Objetivo: Identificar la duración del ayuno perioperatorio entre los pacientes sometidos a cirugías de cáncer gastrointestinal. Método: Estudio de cohorte retrospectivo, por consulta de los registros médicos de 128 pacientes sometidos a cirugías de cáncer gastrointestinal. Resultados: La media de la duración total del ayuno fue de 107,6 horas. La duración total del ayuno se asoció significativamente con el número de síntomas presentados antes $(\mathrm{p}=0,000)$ y después de la cirugía $(\mathrm{p}=0,007)$, la duración de la estancia hospitalaria $(p=0,000)$, transfusión de sangre $(p=0,013)$, tubo nasogástrico $(P=0,003)$, ingreso postoperatorio en la UCI ( $p=0,002)$, muerte postoperatoria $(\mathrm{p}=0,000)$ y duración del ayuno preoperatorio $(\mathrm{p}=0,000)$. Conclusión: La duración del ayuno se asocia con complicaciones que afectan la calidad de la recuperación postoperatoria de los pacientes y el trabajo de enfermería. El equipo de enfermería debe estar alerta en relación a este aspecto y ser responsable de supervisar el interés de los pacientes, no permitiendo la extensión innecesaria del ayuno.

DESCRIPTORES

Procedimientos Quirúrgicos del Sistema Digestivo; Ayuno; Enfermería Perioperatoria; Enfermería Oncológica; Neoplasias del Sistema Digestivo.

\section{REFERENCES}

1. Osland EJ, Memon MA. Early postoperative feeding in resectional gastrointestinal surgical cancer patients. World J Gastrointest Oncol. 2010;2(4):187-91.

2. Laffitte AM, Polakowski CB, Kato M. Early oral re-feeding on oncology patients submitted to gastrectomy for gastric cancer. Arq Bras Cir Dig. 2015;28(3):200-3.

3. Wang ZG, Wang Q, Wang WJ, Qin HL. Randomized clinical trial to compare the effects of preoperative oral carbohydrate versus placebo on insulin resistance after colorectal surgery. Br J Surg. 2010;97(3):317-27. 
4. Dock-Nascimento DB, Aguilar-Nascimento JE, Caporossi C, Faria MSM, Bragagnolo R, Caporossi FS, et al. Safety of oral glutamine in the abbreviation of preoperative fasting; a double-blind, controlled, randomized clinical trial. Nutr Hosp. 2011;26(1):86-90.

5. Keane C, Savage S, McFarlane K, Seigne R, Robertson G, Eglinton T. Enhanced recovery after surgery versus conventional care in colonic and rectal surgery. ANZ J Surg. 2012;82(10):697-703.

6. Varadhan KK, Neal KR, Dejong CH, Fearon KC, Ljungqvist O, Lobo DN. The Enhanced Recovery After Surgery (ERAS) pathway for patients undergoing major elective open colorectal surgery: a meta-analysis of randomized controlled trials. Clin Nutr. 2010;29(4):434-40.

7. Day RW, Cleeland CS, Wang XS, Fielder S, Calhoun J, Conrad C, et al. Patient-Reported Outcomes Accurately Measure the Value of an Enhanced Recovery Program in Liver Surgery. J Am Coll Surg. 2015;221(6):1023-30.

8. Bicudo-Salomão A, Meireles MB, Caporossi C, Crotti PLR, Aguilar-Nascimento JE. Impact of the ACERTO project in the postoperative morbimortality in a university hospital. Rev Col Bras Cir. 2011;38(1):3-10.

9. Braga M, Pecorelli N, Ariotti R, Capretti G, Greo M, Balzano G, et al. Enhanced recovery after surgery pathway in patients undergoing pancreaticoduodenectomy. World J Surg. 2014;38(11):2960-6.

10. Haverkamp MP, Roos MA, Ong KH. The ERAS protocol reduces the length of stay after laparoscopic colectomies. Surg Endosc. 2012;26(2):361-7.

11. Ren L, Zhu D, Wei Y, Pan X, Liang L, Xu J, et. al. Enhanced Recovery After Surgery (ERAS) program attenuates stress and accelerates recovery in patients after radical resection for colorectal cancer: a prospective randomized controlled trial. World J Surg. 2012;36(2):407-14.

12. Bakker N, Cakir H, Doodeman HJ, Houdijk AP. Eight years of experience with Enhanced Recovery After Surgery in patients with colon cancer: Impact of measures to improve adherence. Surgery. 2015;157(6):1130-6.

13. Power S, Kavanagh DO, McConnell G, Cronin K, Corish C, Leonard M, et.al. Reducing preoperative fasting in elective adult surgical patients: a case-control study. Ir J Med Sci. 2012;181(1):99-104.

14. Manchikanti L, Malla Y, Wargo BW, Fellows B. Preoperative fasting before interventional techniques: is it necessary or evidence-based? Pain Physician. 2011;14(5):459-67.

15. Van Osdol AD, Borgert AJ, Kallies KJ, Froman JP, Bottner WA, Shapiro SB. Long-term outcomes of an integrated transfusion reduction initiative in patients undergoing resection for colorectal cancer. Am J Surg. 2015;210(6):990-5.

16. Gunka I, Dostalik J, Martinek L, Gunkova P, Mazur M. Impact of blood transfusions on survival and recurrence in colorectal cancer surgery. Indian J Surg. 2012;75(2):94-101.

17. Cata JP, Wang H, Gottumukkala V, Reuben J, Sessler DI. Inflammatory response, immunosuppression, and cancer recurrence after perioperative blood transfusions. Br J Anaesth. 2013;110(5):690-701.

18. Slim K, Vignaud M. Enhanced recovery after surgery: the patient, the team, and the society. Anaesth Crit Care Pain Med. 2015;34(4):249-50.

19. Hübner M, Addor V, Slieker J, Griesser AC, Lécureux E, Blanc C, et al. The impact of an enhanced recovery pathway on nursing workload: a retrospective cohort study. Int J Surg. 2015;24(Pt A):45-50.

20. Sjetne IS, Krogstad U, Ødegård S, Engh ME. Improving quality by introducing enhanced recovery after surgery in gynaecological department: consequences for ward nursing practice. Qual Saf Health Care. 2009;18(3):236-40.

21. Foss M, Bernard H. Enhanced recovery after surgery: implications for nurses. Br J Nurs. 2012;21(4):221-3.

22. Burch J. What does enhanced recovery mean for the community nurse? Br J Community Nurs. 2009;14(11):490-4.

23. Aroni P, Nascimento LA, Fonseca LF. Assessment strategies for the management of thirst in the post-anesthetic recovery room. Acta Paul Enferm. 2012;25(4):530-6. 